\title{
'Safor' Mandarin: A New Citrus Mid-late Triploid Hybrid
}

\author{
José Cuenca, Pablo Aleza, José Juárez, José A. Pina, and Luis Navarro ${ }^{1}$ \\ Centro de Protección Vegetal y Biotecnología, Instituto Valenciano de \\ Investigaciones Agrarias, Ctra. Moncada a Náquera Km. 4,5, 46113, \\ Moncada, Valencia, Spain
}

Additional index words. embryo rescue, tissue culture, flow cytometry, triploid, seedlessness

World mandarin production rose from 18.3 million tons to 27.9 million tons between the years 2000 and 2007 (FAO, Food and Agriculture Organization, 2009). In Spain, $87 \%$ of mandarin production in the last 5 years has been destined to the fresh fruit market (Intercitrus, Interprofessional Citrícola Española, 2008), which demands high-quality, seedless fruits throughout the marketing season. Therefore, the production of seedless varieties is very important.

Triploid plants are generally considered an evolutionary dead end, because they generally give rise to aneuploid gametes with very low fertility (Otto and Whitton, 2000). Predominantly trivalent and a high number of bivalent and univalent associations are formed during meiosis of citrus triploid hybrids (Frost and Soost, 1968). Moreover, abortion of the megasporogenesis in the period between the embryo-sac first divisions and the fecundated egg cell is common (Fatta Del Bosco et al., 1992). For this reason, citrus triploid hybrids are generally sterile, although they can occasionally produce fruits with very few seeds and induce seed formation in fruits of other cultivars.

Citrus triploid hybrids can be obtained by means of $2 \mathrm{x} \times 2 \mathrm{x}$ hybridizations through the production of unreduced gametes by the female parent (Esen and Soost, 1971). The frequency of unreduced gamete formation depends on the genotype (Esen and Soost, 1971; Luro et al., 2004). Triploid embryos are preferentially found in seeds between onethird and one-sixth smaller than normal seeds and these small seeds generally do not germinate under conventional greenhouse conditions. Embryo rescue from these small seeds is required to reach high germination rates (Navarro et al., 2002). Luro et al. (2004) proposed that Second Division Restitution is the mechanism controlling unreduced gamete formation in clementines, whereas in sweet orange, Chen et al. (2008) proposed First Division Restitution to be the mechanism involved. In these two genetic mecha-

Received for publication 7 Apr. 2010. Accepted for publication 28 Apr. 2010.

This work was jointly financed by the AGL2008-00596-MCI and Prometeo 2008/121 Generalitat Valenciana projects.

${ }^{1}$ To whom reprint requests should be requested; e-maillnavarro@ivia.es. nisms, only one part of the maternal heterozygosity is transmitted to the triploid hybrid and the rate of maternal heterozygosity varies among the loci in relation with the rate of single crossing over between the centromere and a given locus (Ollitrault et al., 2008).

Ploidy level determination by histological methods is too laborious for large-scale analyses. However, ploidy level can be accurately determined relatively rapidly in large populations by flow cytometry (Ollitrault and Michaux-Ferriere, 1992). Embryo rescue and flow cytometry are two indispensable techniques for extensive triploid citrus breeding programs. These techniques allow the efficient recovery of plants from embryos contained in small seeds and enable the ploidy level of regenerated plantlets to be determined quickly and easily with just a small piece of leaf while the plants are still in the test tube (Navarro et al., 2002).

In Spain, there are numerous problems associated with the production season of mandarin cultivars, which include satsumas [Citrus unshiu (Mak.) Marc.], clementines (C. clementina Hort. ex Tan.), and mandarin hybrids. Satsumas and clementines are traditionally harvested from the beginning of September until mid-February. Satsumas produce seedless fruits because they have sterile pollen and ovules. Clementines, the most widely grown mandarins in Spain, are self-incompatible and also produce seedless fruits if grown in isolation. However, their pollen and ovules are viable, and consequently they are able to pollinate and be pollinated by other sexually compatible cultivars. As a result of the demand for lateseason mandarins by international markets, several mid- and late-maturing mandarin hybrids were introduced in Spanish citriculture. These hybrids are self-incompatible, but their pollen and ovules are viable and crosspollinate with clementines, producing fruits with seeds in both groups of cultivars, which causes substantial economic losses.

With a view to solving this problematic situation, a triploid breeding program was started in Spain in 1996. The main objective was to produce new mid- and late-maturing triploid cultivars through sexual hybridization, embryo rescue, and ploidy analysis by flow cytometry (Navarro et al., 2002). Recently we released the late-maturing triploid variety Garbí $[(C$. clementina $\times$ C. tangerina $) \times$ (C. reticulata $\times C$. sinensis)] (Aleza et al., 2010), which reaches optimum maturation during the second half of March. This variety of mandarin is replacing 'Fortune' mandarin (C. clementina $\times C$. tangerina), which reached a peak production of 300,000 tons but is currently being replaced rapidly as a result of its high susceptibility to Alternaria alternata. Another problem is the low fruit quality of 'Hernandina' clementine, our latest maturing clementine, when grafted on 'Carrizo' citrange (Citrus sinensis $\times$ Poncirus trifoliata), which is by far the most predominant rootstock. Fruit peel deteriorates quickly after mid-January, and in practice, no clementine fruits are available by February.

In this article, we describe a new triploid hybrid named 'Safor' mandarin [(C. clementina $\times C$. tangerina $) \times(C$. unshiu $\times C$. nobilis $)]$ characterized by its high quality, seedless fruits, and mid-late ripening season.

\section{Origin}

'Safor' is a new triploid hybrid obtained from a cross between diploid 'Fortune' mandarin and diploid 'Kara' mandarin (C. unshiu $\times$ C. nobilis). Anthers of 'Kara' mandarin were removed from flowers collected in preanthesis and dried in petri dishes over silica gel in a desiccator. Dried dehisced anthers were stored in small petri dishes at $-20{ }^{\circ} \mathrm{C}$ until needed for pollination, usually less than 1 month. Controlled cross-pollination was done by applying one anther from the paternal parent to receptive stigma of 'Fortune' mandarin flowers in Spring 1996. Approximately 100 flowers of 'Fortune' mandarin

Table 1. Summary of fruit quality characteristics of 'Safor' mandarin.

\begin{tabular}{|c|c|c|c|c|c|}
\hline & $2007^{z}$ & 2008 & 2009 & 2010 & Mean $^{y}$ \\
\hline Diameter (mm) & $54 \pm 2$ & $60 \pm 2$ & $50 \pm 2$ & $62 \pm 4$ & $56 \pm 5$ \\
\hline Height (mm) & $50 \pm 3$ & $54 \pm 1$ & $45 \pm 2$ & $57 \pm 4$ & $52 \pm 5$ \\
\hline Weight (g) & $86 \pm 9$ & $114 \pm 6$ & $65 \pm 8$ & $128 \pm 25$ & $98 \pm 28$ \\
\hline $\mathrm{CCI}^{\mathrm{x}}$ & $16 \pm 2$ & $18 \pm 1$ & $15 \pm 1$ & $21 \pm 3$ & $17 \pm 2$ \\
\hline Rind thickness (mm) & $2.2 \pm 0.3$ & $2.6 \pm 0.4$ & $2.5 \pm 0.3$ & $2.6 \pm 0.2$ & $2.5 \pm 0.2$ \\
\hline Segments per fruit & $9.4 \pm 0.3$ & $10.1 \pm 0.7$ & $10.7 \pm 0.4$ & $10.3 \pm 0.4$ & $10.1 \pm 0.6$ \\
\hline Soluble solids (\%) & $15.9 \pm 1.1$ & $13.8 \pm 1.1$ & $16.8 \pm 0.2$ & $13.7 \pm 0.9$ & $15.1 \pm 1.5$ \\
\hline Acids $(\%)$ & $1.9 \pm 0.2$ & $1.6 \pm 0.3$ & $2.6 \pm 0.2$ & $1.6 \pm 0.2$ & $1.9 \pm 0.5$ \\
\hline Juice content $(\%)$ & $43 \pm 2$ & $42 \pm 4$ & $39 \pm 2$ & $43 \pm 3$ & $42 \pm 2$ \\
\hline
\end{tabular}

${ }^{\mathrm{z}}$ Averaged over five sample dates per year from January to March. Each sample comprised 10 fruits and was collected every $15 \mathrm{~d}$.

${ }^{y}$ Average of 4 years.

${ }^{x}$ Citrus Color Index according methodology described by Jiménez-Cuesta et al. (1981). 
were pollinated and 50 fruits were collected, which contained 81 small seeds produced by $2 \mathrm{x} \times 2 \mathrm{x}$ crosses. Eighty-one embryos were isolated from these seeds and cultured in vitro in the culture medium described by Murashige and Skoog (1962) with $50 \mathrm{~g} \cdot \mathrm{L}^{-1}$ sucrose, 500 $\mathrm{mg} \cdot \mathrm{L}^{-1}$ malt extract supplemented with vitamins (100 mg. $\mathrm{L}^{-1}$ i-inositol, $1 \mathrm{mg} \cdot \mathrm{L}^{-1}$ pyridoxine hydrochloride, $1 \mathrm{mg} \cdot \mathrm{L}^{-1}$ nicotinic acid, 0.2 $\mathrm{mg} \cdot \mathrm{L}^{-1}$ thiamine hydrochloride, $4 \mathrm{mg} \cdot \mathrm{L}^{-1} \mathrm{gly}-$ cine), and $8 \mathrm{~g} \cdot \mathrm{L}^{-1}$ Bacto agar [Murashige and Skoog (MS) culture media]. After germination, 81 plantlets were subcultured in an elongation medium, which consisted of the MS culture media without malt extract. Cultures were maintained at $24 \pm 1{ }^{\circ} \mathrm{C}, 60 \%$ humidity, and 16-h daily exposure to $40 \mu \mathrm{E}$ $\mathrm{m}^{-2} \cdot \mathrm{s}^{-1}$ illumination. Ploidy level of all plants was analyzed by flow cytometry in the flow cytometer Ploidy Analyzer (Partec ${ }^{\circledR} \mathrm{GmbH}$, Münster, Germany). Small pieces of leaves, measuring $\approx 0.5 \mathrm{~cm}^{2}$, were taken from the in vitro-growing plants and chopped together with a piece of leaf from a control diploid plant, placed in a Partec ${ }^{\circledR}$ CyStain ultraviolet Precise P nuclei extraction buffer, stained with DAPI, and analyzed in the cytometer. Seventyeight plantlets were triploid, were transplanted to the greenhouse, and in 1998, 1 year later, were grafted onto 'Carrizo' citrange rootstock for field evaluation at IVIA plots (Instituto Valenciano de Investigaciones Agrarias, located in Moncada, Valencia, Spain). 'Safor' mandarin flowered for the first time in Spring 2001. After 3 years of production, this variety was selected because of its high fruit quality and propagated in two additional evaluation plots to confirm its uniformity and stability. Ploidy level of 'Safor' mandarin was confirmed by cytology using the hematoxylin staining technique of Sass (1958) and modified by Tusa et al. (1990).

\section{Description}

Descriptions are based on data taken from five trees: the original hybrid tree, grafted on 'Carrizo' citrange growing at an IVIA plot, was used for the first screening of triploid progenies. Two trees, top-worked on 3-yearold 'Carrizo' citrange rootstock growing at a different IVIA plot, were used for secondary evaluation of the selected hybrids, and two trees top-worked on 20-year-old 'Valencia Late' sweet orange [C. sinensis L. (Osb.)] grafted on 'Troyer' citrange $(C$. sinensis $\times$ $P$. trifoliata) growing at a plot located in Museros, Valencia, belonging to the citrus cooperative ANECOOP. Data were collected essentially following the "Guidelines for the Conduct of Tests for Distinctness, Uniformity and Stability," Citrus L. Group 1 Mandarins, from the International Union for the Protection of new Varieties of Plants (UPOV, International Union for the Protection of New Varieties of Plants, 2009). No significant differences were found in any parameter among tress growing in the different plots. Furthermore, the description was confirmed by comparison with first-year fruits produced by three other trees of 'Safor'
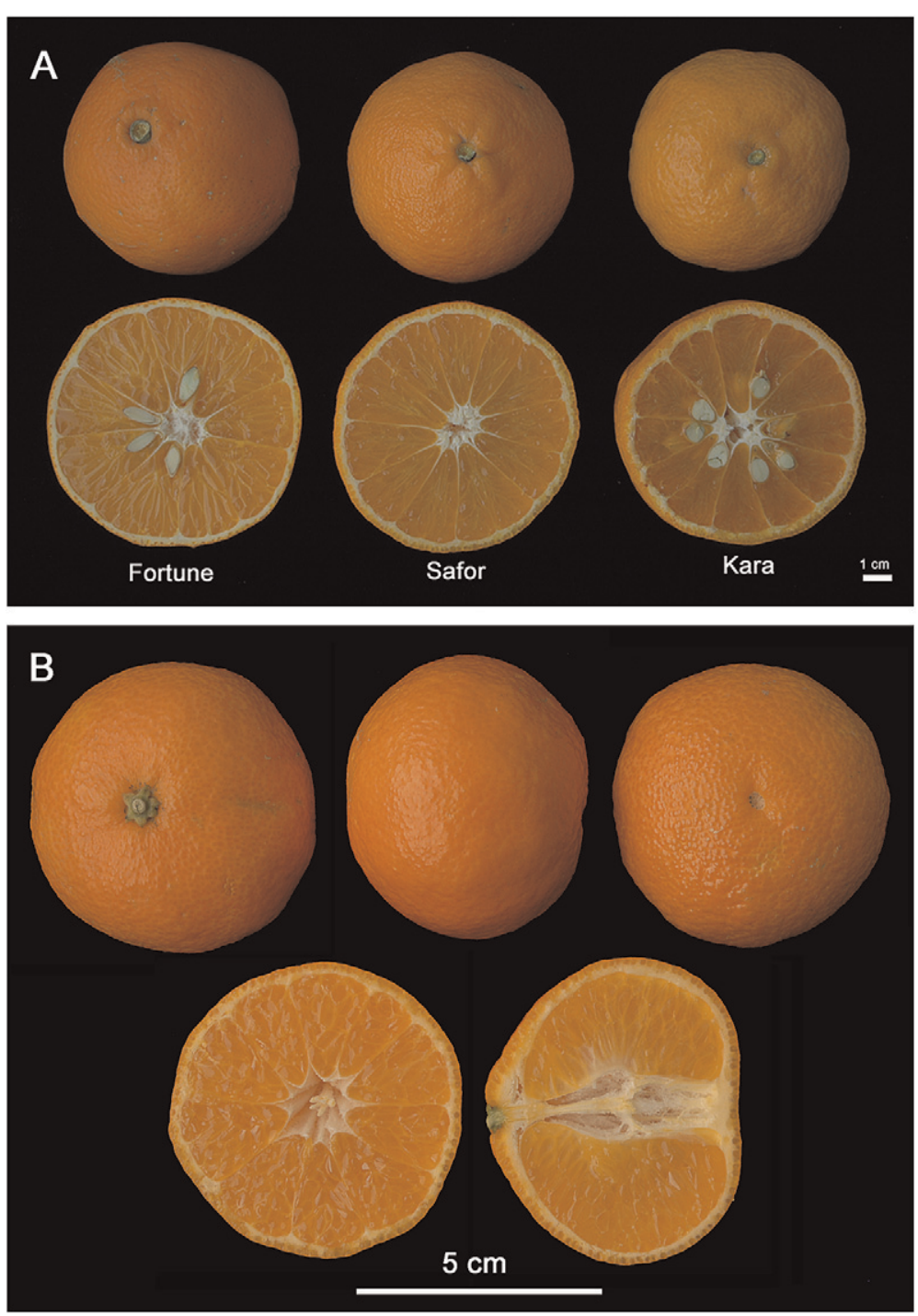

Fig. 1. (A) Fruits of 'Safor' mandarin and its parents. (B) Fruits of triploid 'Safor' mandarin.

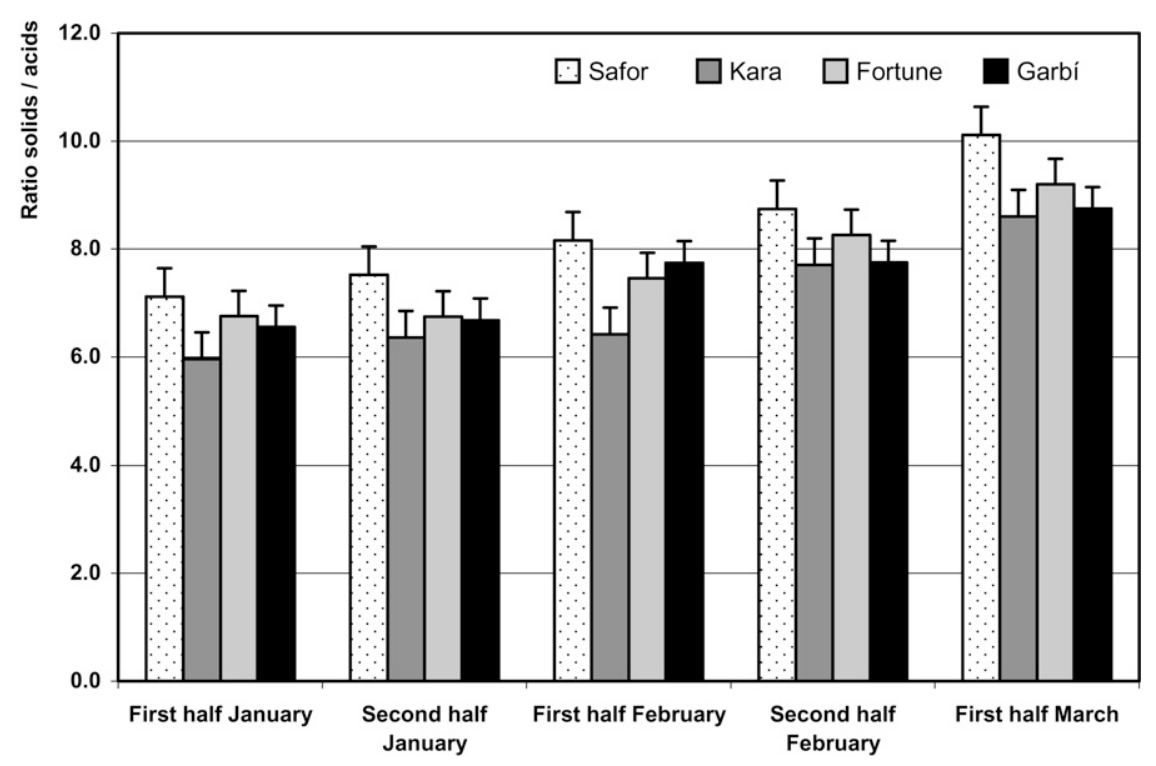

Fig. 2. Comparison of the ratio solids/acids evolution between 'Safor' mandarin, its parents, and 'Garbí' mandarin. Data are the average of three seasons and the bars represent the SD. 
mandarin top-worked on 26-year-old 'Newhall' sweet orange grafted on 'Carrizo' citrange growing in an experimental plot in Villarreal, Castellón. Data of 'Safor' mandarin was compared with 'Garbí', 'Fortune', and 'Kara' mandarins.

The 'Safor' mandarin tree is vigorous, obloid in shape, and exhibits drooping growth. Main branches have thorns of $\approx 16$ $\mathrm{mm}$ in length, although new branches do not have thorns.

'Safor' mandarin fruits are seedless in an open-pollinated environment. They reach optimum maturity in the second half of February, when the ratio of solids/acids of the fruits can reach eight, although they can be harvested from mid-February until the end of March. Fruit characteristics are described in Table 1. Fruits are easy to peel like 'Kara' mandarin, obloid in shape with the proximal part slightly rounded with a diameter between 51 and $61 \mathrm{~mm}$, height between 47 and $57 \mathrm{~mm}$, weight between 70 and $126 \mathrm{~g}$, and the broadest part is toward the distal end, circular shape in the transverse section with an absent neck (Fig. 1A-B). Fruits do not have areola or persistent style nor do they have radial grooves at the distal end. Fruit rind is orangered in color (Citrus Color Index $=17$ ) (Jiménez-Cuesta et al., 1981), similar to 'Nova' mandarin with reduced thickness (average $2.5 \mathrm{~cm}$ ). The albedo is white and the flesh is orange in color. Fruits lack a navel and have absent or weak rudimentary segments and an intermediate number of welldeveloped segments (nine to 11 segments per fruit). At maturity, the fruits have high total soluble sugars and acidity content with 15.1 ${ }^{\circ}$ Brix and $\approx 1.9 \%$ of acid concentration. The solids/acids ratio increases through the season (Fig. 2), primarily because of the increase in solids and maintenance of acids. If we compare the ratio of 'Safor' mandarin with its parents and 'Garbí' mandarin at the optimum ripening stage (second half of February), the ratio of 'Safor' mandarin (8.7) is higher than 'Garbí' (7.8), 'Fortune' (8.3), and 'Kara' mandarins (7.7) mainly as a result of the lower quantity of acids in 'Safor' mandarin. The flavor is slightly acidic like 'Fortune' mandarin with medium strength of fiber, easyto-eat texture of the segments, and a pleasant aroma, resembling 'Fortune' mandarin.

The leaves of 'Safor' mandarin are evergreen and simple with a long leaf blade (average length $13.2 \mathrm{~cm}$ ) and broad width of the leaf blade (average $4.7 \mathrm{~cm}$ ). The margin of the leaves has crenate-festoneate incisions and acute-shaped apex. The petiole is medium in length (average $14.7 \mathrm{~mm}$ ) with very small wings. Leaves are characteristic and very similar to 'Kara' mandarin.

'Safor' mandarin flowers are hermaphrodite and white. Flowering occurs in April in Moncada (Valencia, Spain) and many borne flowers are produced like 'Garbí' mandarin. 'Safor' mandarin pollen fertility is very low with only $0.2 \%$ of pollen grains germinating in vitro (lower fertility than 'Garbí' mandarin) as compared with 'Fortune' mandarin pollen grains, of which over $82 \%$ germinated.
Controlled cross-pollinations have been carried out among 'Safor' mandarin, 'Loretina' clementine, and 'Fortune' mandarin. Fifty flowers of 'Loretina' clementine with receptive stigma were pollinated by applying one anther from 'Safor' mandarin and only seedless fruits were obtained. Also, 50 flowers of 'Safor' mandarin were pollinated with pollen from 'Fortune' mandarin and no seeds were obtained. In open pollination, seeds were very rare in fruits of 'Safor' mandarin. These results confirm that this new triploid cultivar is seedless and that seed formation in clementines is not induced by cross-pollination.

Trees of 'Safor' mandarin and several mandarin varieties are planted in experimental plots at IVIA that have a high level of $A$. alternata inoculum. 'Fortune' mandarin and 'Minneola' tangelo $(C$. paradisi $\times C$. tangerina) trees display severe $A$. alternata symptoms in leaves and fruits, and 'Nova' mandarin trees display mild to medium symptoms, whereas in a 6-year observation period, no symptoms have ever been observed in the leaves or fruits of 'Safor' mandarin.

Table 2. Genetic analysis with simple sequence repeat markers of 'Safor' mandarin and different cultivars of mandarin. ${ }^{z}$

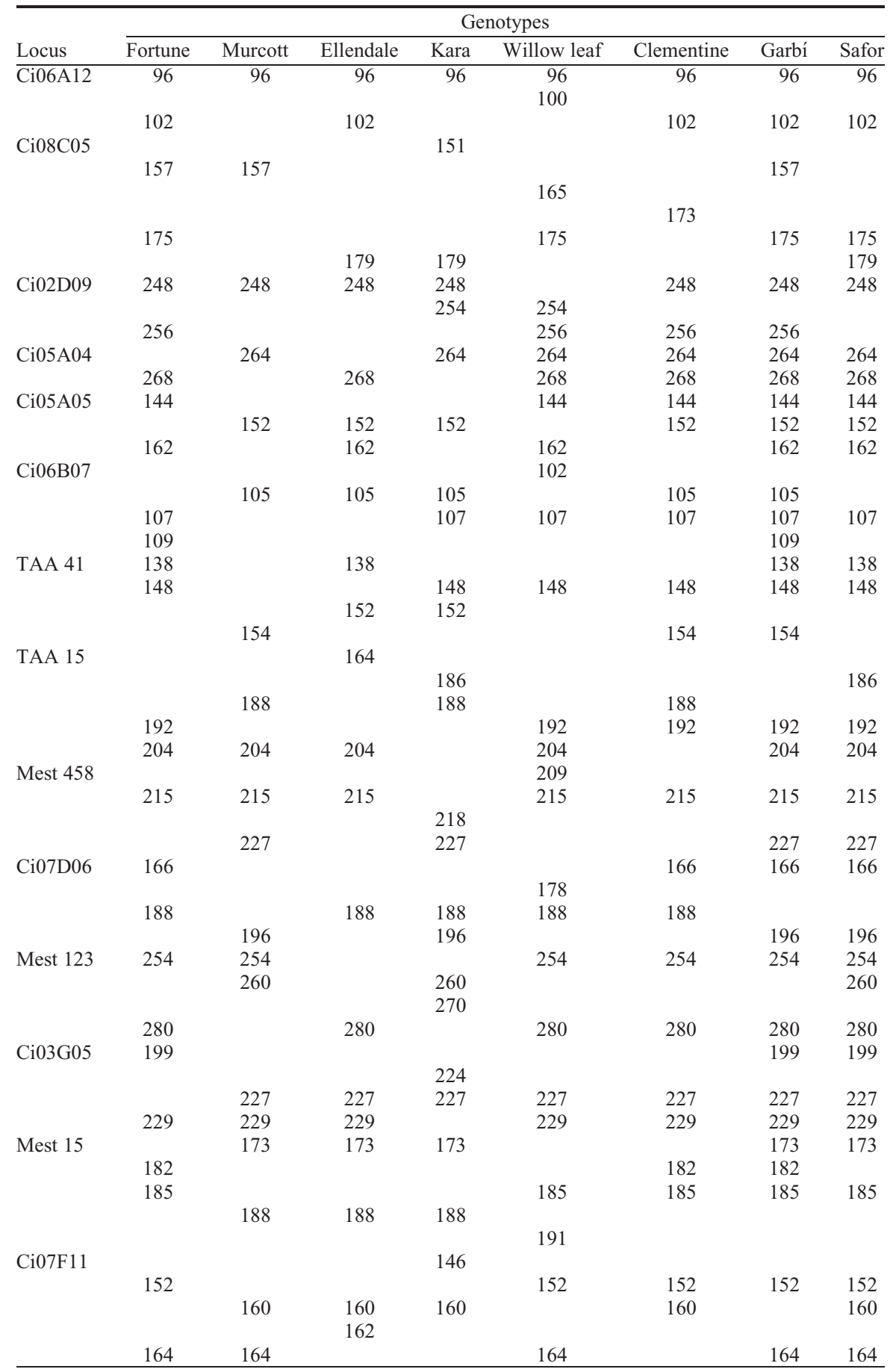

${ }^{\mathrm{z}}$ Numbers indicate the size, in nucleotides (nt), of the alleles for each simple sequence repeat marker. 
'Safor' mandarin was analyzed with 14 simple sequence repeat (SSR) markers by capillary electrophoresis. Table 2 shows the size of alleles in nucleotides for each SSR marker (Froelicher et al., 2008; Kijas et al., 1997; Luro et al., 2008) and these results clearly distinguish 'Safor' mandarin from other cultivated commercial cultivars and from triploid 'Garbí' mandarin. Genetic analyses with the microsatellite loci Ci05A05, TAA 15, Mest 123, Ci03G05, and Ci07F11 indicated that the origin of 'Safor' mandarin was the unreduced gamete of 'Fortune' mandarin. This was indicated by the presence of two alleles of this cultivar and one allele of 'Kara' mandarin. Also, molecular markers help protect breeders' rights and control traceability of nursery-propagated plants.

The overall characteristics of 'Safor' mandarin would indicate that its fruits could be collected during February and even up until the first week of March. This will fill an important gap in the production calendar of seedless mandarins for the Spanish citrus industry.

\section{Availability}

Protection of Plant Breeders' Rights for this cultivar have been requested in the European Union, Morocco, Egypt, South Africa, and Turkey and also a U.S. Plant Patent has been requested. IVIA holds the rights of the cultivar and the Fundación de la Comunidad Valenciana para la Investigación Agroalimentaria (AGROALIMED) is handling these rights for commercial propagation under royalty agreements with licensed nurseries. Pathogen-free plants of 'Safor' mandarin have been obtained by shoot-tip grafting in vitro according to the methodology described by Navarro et al. (1975) and healthy budwood was released in Summer 2008 to 22 Spanish nurseries that signed propagation agreements to produce certified plants. Approximately 50,000 certified plants of 'Safor' mandarin will be planted by growers in 2010, which is the first year it has been available at nurseries.

\section{Literature Cited}

Aleza, P., J. Cuenca, J. Juárez, J.A. Pina, and L. Navarro. 2010. 'Garbí' mandarin: A new latematuring triploid hybrid. HortScience 45:139141.

Chen, C., M.T. Lyon, D. O’Malley, C.T. Federici, J. Gmitter, J.W. Grosser, J.X. Chaparro, M.L. Roose, and F.G. Gmitter. 2008. Origin and frequency of $2 \mathrm{n}$ gametes in Citrus sinensis $x$ Poncirus trifoliata and their reciprocal crosses. Plant Sci. 174:1-8.

Esen, A. and R.K. Soost. 1971. Unexpected triploids in citrus: Their origin, identification and possible use. J. Hered. 62:329-333.

FAO, Food and Agriculture Organization. 2009. 27 Nov. 2009. <http://faostat.fao.org/site/567/ default.aspx\#ancor>.

Fatta Del Bosco, S., G. Matranga, and G. Geraci. 1992. Micro and macro-sporogenesis of two triploid hybrids of citrus. Proc. of 7th International Citrus Congress. International Society of Citriculture, Acireale, Italy. 1:122-124.

Froelicher, Y., D. Dambier, J.B. Bassene, G. Costantino, S. Lotfy, C. Didout, V. Beaumont, P. Brottier, A.M. Risterucci, F. Luro, and P. Ollitrault. 2008. Characterization of microsatellite markers in mandarin orange (Citrus reticulata Blanco). Molecular Ecology Resources 8:119-122.

Frost, H.B. and R.K. Soost. 1968. Seed reproduction, development of gametes and embryos, $\mathrm{p}$. 290-324. In: Reuther, W., L.D. Batchelor, and H.B. Webber (eds.). The citrus industry. Vol. 2. University of California, Berkeley, CA.

Intercitrus, Interprofesional Citrícola Española. 2008. Datos del sector. 27 Nov. 2009. <http://www. intercitrus.org/ndsite.php?section=sectorCitricola DatosDelSector>.

Jiménez-Cuesta, M., J. Cuquerella, and J.M. MartínezJávega. 1981. Determination of a color index for citrus fruit degreening. Proc. of 4th International Citrus Congress. International Society of Citriculture, Tokyo, Japan. 2:750-752.

Kijas, J.M.H., M.R. Thomas, J.C.S. Fowler, and M.L. Roose. 1997. Integration of trinucleotide microsatellites into a linkage map of citrus. Theor. Appl. Genet. 94:701-706.

Luro, F., G. Costantino, J.F. Terol, X. Argout, T. Allario, P. Wincker, M. Talon, P. Ollitrault, and R. Morillon. 2008. Transferability of the ESTSSRs developed on Nules clementine (Citrus clementina Hort ex Tan) to other citrus species and their effectiveness for genetic mapping. BMC Genomics 9:1-13.

Luro, F., F. Maddy, C. Jacquemond, Y. Froelicher, R. Morillon, D. Rist, and P. Ollitrault. 2004. Identification and evaluation of diplogyny in clementine (Citrus clementina) for use in breeding. In XI Eucarpia Symposium on Fruit Breeding and Genetics. Acta Hort. 663:841-847.

Murashige, T. and F. Skoog. 1962. A revised medium for rapid growth and bioassays with tobacco tissue cultures. Physiol. Plant. 15:473-479.

Navarro, L., C.N. Roistacher, and T. Murashige. 1975. Improvement of shoot-tip grafting in vitro for virus-free citrus. J. Amer. Soc. Hort. Sci. 100:471-479.

Navarro, L., J. Juárez, P. Aleza, and J.A. Pina. 2002. Recovery of triploid seedless mandarin hybrids from $2 n \times 2 n$ and $2 n \times 4 n$ crosses by embryo rescue and flow cytometry. Proc. of the 10th IAPTC\&B Congress, Plant Biotechnology 2002 and Beyond, Orlando, FL. p. 541-544.

Ollitrault, P. and N. Michaux-Ferriere. 1992. Application of flow cytometry for citrus genetic and breeding. In Proceeding 7th International Citrus Congress, International Society of Citriculture, Acireale, Italy. 1:193-198.

Ollitrault, P., D. Dambier, F. Luro, and Y. Froelicher. 2008. Ploidy manipulation for breeding seedless triploid citrus. Plant Breed. Rev. 20:323-354.

Otto, S.P. and J. Whitton. 2000. Polyploid incidence and evolution. Annu. Rev. Genet. 34: 401-437.

Sass, J.E. 1958. Botanical microtechnique. Iowa State Univ. Press, Ames, IA. p. 73-75.

Tusa, N., J.W. Grosser, and F.G. Gmitter. 1990. Plant regeneration of 'Valencia' sweet orange, 'Femminello' lemon and the interspecific somatic hybrid following protoplast fusion. J. Amer. Soc. Hort. Sci. 115:1043-1046.

UPOV, International Union for the Protection of New Varieties of Plants. 2009. 27 Nov. 2009. $<$ http://www.upov.int/en/publications/tg-rom/ tg201/tg_201_1.pdf>. 